\title{
MACAÉ ALÉM DO PETRÓLEO: DIVERSIFICAÇÃO SOCIOECONÔMICA ATRAVÉS DO TURISMO**
}

Erick da Cunha Coelho Zickwolff ${ }^{1}$

ORCID: https://orcid.org/0000-0002-2678-1744

Glauber Henrique Santos Caldas ${ }^{2}$

ORCID: https://orcid.org/0000-0001-6534-3301

Vânia Hatab Coelho ${ }^{3}$

ORCID: https://orcid.org/0000-0002-0564-349X

Aline César Jesus ${ }^{4}$

ORCID: https://orcid.org/0000-0003-2328-3843

Natasha Ribeiro Bantim 5

ORCID: https://orcid.org/0000-0001-7554-1459

Recebido em: 14/06/2021.

Publicado em:

30/09/2021.

\section{RESUMO}

O presente artigo tem como objetivo analisar as perspectivas de ampliação da atividade turística no município fluminense de Macaé, levando em conta a recente crise econômica vivida pela cidade, entre os anos de 2014 e 2018, além do atual quadro de incertezas geradas pela pandemia da Covid19. Para uma melhor contextualização do tema, foi realizado um breve levantamento acerca do desenvolvimento econômico macaense, desde suas origens agrárias até o estabelecimento da base de operação para as atividades de prospecção e de produção da Bacia de Campos, pela Petrobras, e a construção da identidade de "Capital Nacional do Petróleo". As razões que contribuíram para o cenário da crise da década de 2010 também foram investigadas, mostrando que, devido ao atual estágio do capitalismo global, alguns acontecimentos internacionais - como a variação nos preços do barril de petróleo - podem ter um impacto tão significativo para uma cidade brasileira, quanto a situação política do próprio país. Para que se pudesse pensar nas possibilidades do desenvolvimento de um turismo mais sustentável em Macaé, tornou-se necessário que se perquirisse sobre o momento vivido no município hoje, com a

\footnotetext{
${ }^{1}$ Professor de Turismo da FAETEC, Rio de Janeiro-RJ, Brasil.

2 Turismólogo da Secretaria Adjunta de Turismo da Prefeitura de Macaé-RJ, Brasil.

${ }^{3}$ Secretaria Adjunta de Turismo da Prefeitura de Macaé-RJ, Brasil.

${ }^{4}$ Turismóloga da Secretaria Adjunta de Turismo da Prefeitura de Macaé-RJ, Brasil.

${ }^{5}$ Coordenadora Técnica do Eixo Turismo, Hospitalidade e Lazer - ETEJK-FAETEC-RJ, Rio de Janeiro, Brasil.
}

\section{(c) $\mathrm{EY}-\mathrm{MO}-\mathrm{EA}$}


presença e circulação do coronavírus (Sars-CoV-2) alterando o cotidiano, obrigando o estabelecimento de novas práticas diárias, além da gradual retomada das atividades relacionadas com o petróleo. A conclusão deste exercício, ao mesmo tempo analítico e imaginativo, aponta para a necessidade do estabelecimento de parcerias entre o poder público municipal, através de suas diversas pastas - com destaque para a Secretaria Adjunta de Turismo -, a iniciativa privada e as instituições de ensino superior e técnico com sede na cidade, inclusive com uma aproximação regional com os diversos municípios da região turística da Costa do Sol, a qual pertence.

Palavras chave: turismo; Macaé; crise econômica; desenvolvimento.

\title{
MACAÉ BEYOND OIL: SOCIOECONOMIC DIVERSIFICATION THROUGH TOURISM
}

\begin{abstract}
This article aims to analyze the perspectives of tourist activity in Macaé-RJ, taking into account the recent economic crisis experienced by the city between 2014 and 2018, in addition to the current picture of uncertainties generated by the Covid-19 pandemic. For a better contextualization of the theme, a brief survey was carried out on the local economic development, from its agrarian origins, through the establishment of the operating base for prospecting and production activities in the Bacia de Campos, by Petrobras, and the construction of Macaé's identity as the "National Capital of Petroleum". The reasons that contributed to the crisis scenario of the $2010^{\text {ee }} \mathrm{s}$ were also investigated, showing that, due to the current stage of global capitalism, some international events - as the variation in the barrel of oil prices - can have as significant an impact on a Brazilian city as the political situation in the country itself. So, for one to think about the possibilities for the development of a more sustainable tourism in Macaé, it became necessary to inquire about the moment lived in the city today, with the presence and circulation of the coronavirus (Sars-CoV-2) changing the daily life, in addition to the gradual resumption of oil- related activities. The conclusion of this exercise, at the same time analytical and imaginative, points to the need to establish partnerships between the municipal government, through its various folders - with emphasis on the Secretaria Adjunta de Turismo, the private and higher and technical education institutions based in the city, including a regional approach with the various municipalities of the tourist region of Costa do Sol, to which it belongs.
\end{abstract}

Keywords: tourism; Macaé; economic crisis; development.

\section{MACAÉ MÁS ALLÁ DEL PETRÓlEO: DIVERSIFICACIÓN SOCIOECONÓMICA A TRAVÉS DEL TURISMO}

\section{RESUMEN}

Este artículo tiene como objetivo analizar las perspectivas de expansión de la actividad turística en la ciudad de Macaé-RJ, teniendo en cuenta la reciente crisis económica vivida por la ciudad entre 2014 y 2018, además del panorama actual de incertidumbres generadas por la pandemia Covid-19. Para una mejor contextualización del tema, se realizó una breve búsqueda sobre el desarrollo económico de Macaé, desde sus orígenes agrarios, pasando por el establecimiento de la base operativa de las actividades de prospección y producción en la Bacia de Campos, por parte 
de Petrobras, y la construcción de su identidad como la "Capital Nacional del Petróleo". También se investigaron las razones que contribuyeron al escenario de crisis de la década de 2010, mostrando que, debido a la etapa actual del capitalismo global, algunos eventos internacionales como la variación de los precios del barril de petróleo - puede tener un impacto tan significativo en una ciudad brasileña como la situación política del propio país. Para pensar en las posibilidades de desarrollo de un turismo más sostenible en Macaé, se hizo necesario indagar sobre la situación actual de la ciudad, con la presencia y circulación del coronavirus (Sars-CoV-

2) alterando la vida cotidiana, además de la paulatina reanudación de las actividades petroleras. La conclusión de este ejercicio, a la vez analítico e imaginativo, apunta a la necesidad de establecer alianzas entre el gobierno municipal, a través de sus distintas carteras - con énfasis en el Secretaria Adjunta de Turismo - el sector privado e instituciones de educación superior y técnica con sede en la ciudad, incluyendo un acercamiento regional con los distintos municipios de la región turística de la Costa do Sol, a la que pertenece.

Palabras clave: Turismo; Macaé; Crisis Económica; Desarrollo.

\section{INTRODUÇÃO}

O município de Macaé apresenta uma rica história que remonta ao início do século XVII, quando Portugal, sob o domínio espanhol, faz erigir, nas terras que futuramente a delimitarão, uma pequena aldeia formada por cerca de duzentos indígenas aculturados e alguns portugueses (LÔBO JÚNIOR et al., 1990). Desde então, Macaé passou por diversas transformações impulsionadas por diferentes atividades econômicas até que, na década de 1970, sobreveio sua mudança mais profunda, quando recebeu em seu território a base de exploração de petróleo da Petrobras. A partir daquele momento, viu sua população crescer vertiginosamente, presenciou a expansão imobiliária, o surgimento de comunidades de baixa renda, a chegada de empreendimentos hoteleiros, a construção de um aeroporto, a implementação de cursos de ensino superior - coroada pela edificação da Cidade Universitária - e iniciou sua metamorfose, de singela "Princesinha do Atlântico" à portentosa "Capital Nacional do Petróleo".

Objetivando analisar as perspectivas da ampliação da atividade turística em Macaé, para além de sua segmentação de negócios estritamente relacionada com a cadeia produtiva do petróleo, este artigo realiza um mergulho no passado do município, procurando deslindar a história de seu desenvolvimento econômico e social, permitindo a compreensão do recente cenário da crise relacionada ao setor petrolífero, ocorrida entre os anos de 2014 e 2018 e do debate acerca do futuro desta atividade econômica muito criticada por ambientalistas e por todos os que se preocupam com a questão do aquecimento global. Também foi levada em conta a atual 
pandemia de Covid-19 que assola não só o Brasil, mas todo o mundo e que mudou bastante a forma de vida cotidiana das pessoas. Desta forma, pensar um futuro mais sustentável para o turismo macaense sem ter por base a história local, as relações regionais, nacionais e globais que o influenciam além do panorama de um mundo pós-pandêmico seria, nada mais, que um exercício estéril.

\section{METODOLOGIA}

Para a realização deste artigo, de caráter qualitativo, os autores se valeram do emprego de revisão bibliográfica, utilizando-se de livros, artigos acadêmicos e sítios da internet e se empenhando em uma análise crítica acerca da atividade turística de Macaé, bem como no reconhecimento dos fatores históricos, sociais e econômicos que fizeram com que, ao longo dos anos e, em especial, na última década, o município experimentasse diferentes momentos de desenvolvimento e estagnação. Para a identificação dos artigos utilizados no trabalho, lançaram mão da ferramenta virtual "Google Acadêmico", através de entradas de palavras-chave como “turismo e Macaé”, “turismo de negócios e Macaé” e "petróleo, desenvolvimento e Macaé”, optando-se por utilizar aqueles produzidos a, no máximo, dez anos - do ano de 2011 em diante e que trouxessem informações relevantes para o debate em questão. Com relação aos livros selecionados, não houve uma seleção de caráter temporal, já que parte da teoria ainda em voga é anterior ao período selecionado dos artigos. Ainda assim, são obras específicas da área do turismo que possuem conceitos e definições válidas para servir como base e arcabouço para a edificação das discussões propostas.

Tendo como objetivo pensar as perspectivas da continuidade do desenvolvimento da atividade turística local, também se corporificou um exercício imaginativo, baseado nas experiências de outras localidades e em previsões acerca do panorama pós-pandêmico traçado por diferentes especialistas, sem olvidar das ações realizadas pela Secretaria Adjunta de Turismo da Prefeitura de Macaé - em parceria com diferentes órgãos públicos e com a iniciativa privada. Assim, foram propostas algumas sugestões e vislumbradas possibilidades para o futuro do turismo macaense, atentando-se para os aspectos sustentáveis de tal empreitada, pensando no benefício do maior número de pessoas, do próprio município e sua região circunvizinha, bem como do meio ambiente local. 
Quanto à sua estrutura, o artigo apresenta quatro seções, além das considerações finais. $\mathrm{Na}$ primeira delas, é realizado um breve percurso sobre as atividades econômicas mais importantes desenvolvidas em Macaé, desde os primeiros assentamentos, até a atualidade. Em seguida, o foco passa a ser a relação estabelecida entre o município e a atividade petrolífera, com destaque para a presença da Petrobras em terras macaenses. A terceira seção se fixa na análise da crise econômica verificada na cidade durante a década de 2010, diretamente relacionada à exploração do petróleo. Na sequencia, tem lugar a análise da atividade turística, desde meados do século XX até os dias de hoje, além de sua relação com as outras atividades econômicas locais e seu potencial de desenvolvimento. Por fim, tecemos as considerações finais que apontam algumas conclusões tiradas da pesquisa realizada.

\section{A ECONOMIA DE MACAÉ AO LONGO DA HISTÓRIA}

Nas últimas décadas, uma das principais fontes de renda de Macaé provém do recebimento de royalties e participações especiais, por conta do estabelecimento da infraestrutura montada no município para atender às atividades relacionadas à exploração do petróleo. Leal e Serra explicam que:

Sobre o território que atende à produção petrolífera são imobilizados capitais cuja função deixa de existir quando do esgotamento do petróleo. São estruturas industriais, equipamentos de infraestrutura terrestre e portuária, escritórios de serviços, que se cristalizam nessas regiões e que, muitas vezes, podem responder pela dinâmica de crescimento local ou regional. É somente a qualidade finita desses impactos territoriais e não sua magnitude, que pode justificar a necessidade crucial de aplicar parte dos recursos de royalties nas regiões produtoras [...] se uma região é intensamente impactada pela atividade petrolífera, maior será, ceteriparibus, seu esvaziamento econômico quando do fim das reservas. (2013, p. 17-18).

Entretanto, foi apenas na década de 1970 que a relação entre Macaé e o petróleo começou a se constituir e, muito antes disso, diversas atividades econômicas tiveram lugar em suas terras. Os primeiros relatos escritos sobre a região onde hoje se localiza o município de Macaé dão conta de sua ocupação pelo povo indígena Goitacá, que por serem exímios pescadores, extraíam das águas do mar e dos rios sua principal fonte de alimento. Com a chegada dos europeus neste 
território, ainda no século XVI, uma relação de desconfiança e inimizade irreconciliável se desvelou entre os portugueses e os goitacás, ao mesmo tempo em que laços de cordialidade foram estreitados entre estes últimos e os franceses, com quem estabeleceram trocas, através do escambo do pau-brasil, abundante na região, por miçangas, espelhos, ferramentas e outras bugigangas (LÔBO JÚNIOR et al., 1990).

Quando, em 1534, as terras descobertas por Portugal no ano de 1500 passaram a ser divididas em Capitanias Hereditárias pela Coroa, visando aumentar o controle das atividades econômicas e estimular o desenvolvimento de diferentes partes do vasto território, o Rio Macaé serviu de marco delimitador entre duas delas: São Tomé, ao norte, e São Vicente, ao sul. Porém, demorariam ainda 81 anos para que fosse levantado um primeiro aldeamento nessas paragens, formado por alguns portugueses e duas centenas de indígenas catequizados, provavelmente provenientes de outro povo que não o Goitacá (LÔBO JÚNIOR et al., 1990).

Já em 1627, um grupo formado por militares, que ficou conhecido como “Os Sete Capitães”, requisitaram ao Governador do Rio de Janeiro, Martins Afonso de Sá, uma sesmaria que abarcava as terras entre o Rio Macaé e o Cabo de São Tomé - hoje pertencente ao município de Campos dos Goytacazes - e em 1630, alguns padres da Companhia de Jesus pleitearam as terras que se localizavam ao sul do território dos capitães, entre os rios Macaé e Leripe - que atualmente faz parte do município de Rio das Ostras. Estas duas ocupações são consideradas, efetivamente, como o embrião do futuro município de Macaé (FRANCO, 2021).

Ao longo do século XVIII, após o rearranjo das terras pertencentes aos dois núcleos anteriores, a mando do rei de Portugal, entre os padres jesuítas que seriam expulsos da colônia em 1759, os herdeiros dos "Sete Capitães", além de um grupo de frades beneditinos e do General Salvador Correa de Sá e Benevides, iniciou-se o cultivo da lavoura de cana-de-açúcar, com a exploração da mão de obra de africanos escravizados, cujo tráfico era extremamente lucrativo. Com isso, aos poucos, as atividades relacionadas com a extração de madeira, a produção de alimentos agrícolas e a pecuária - para o abastecimento do mercado interno - foram dando lugar à exportação da cana (FRANCO, 2021).

Com o passar do tempo e o aumento da população local, já no século XIX - mais precisamente no ano de 1813 - foi solicitada ao Príncipe Regente D. João VI - chegado ao Brasil em 1808, fugindo da ocupação das tropas de Napoleão em Portugal - a criação de uma vila, o que se consolidou no dia 29 de julho daquele ano, tendo o antigo arraial sido renomeado como Vila 
de São João de Macahé. Apesar de, em 15 de abril de 1846, Macaé ter sido elevada à categoria de cidade, a data que ainda é comemorada como sendo a de seu aniversário permaneceu sendo 29 de julho. Durante todo esse período a produção açucareira seguiu como a principal atividade econômica macaense, mas cresceu a difusão da cultura do café em sua região serrana, devido ao solo e à condição climática do lugar. (LÔBO JÚNIOR et al., 1990).

Ainda no século XIX, o porto macaense de Imbetiba se destacava como um dos dez mais importantes do Brasil em volume de exportações, gerando a cobrança por parte de sua população da instalação de uma alfândega, o que se concretizou no dia 06 de dezembro de 1896. A cidade ainda contava com o canal artificial Macaé-Campos e com linhas férreas para o escoamento de sua produção agrícola. Naquele momento o destaque ficava por conta do Engenho Central de Quissamã, grande produtor de açúcar e aguardente. Aliás, os atuais municípios de Quissamã e de Carapebus fizeram parte de Macaé até o final do século XX, antes de se emanciparem, nos anos de 1989 e 1997, respectivamente (LÔBO JÚNIOR et al., 1990).

Tendo chegado ao fim o regime escravocrata no país, em 1888, o fim do século XIX e o início do século XX foram marcados pela substituição da mão de obra formada por africanos e seus descendentes alforriados, pela de imigrantes europeus, que passaram a se concentrar na região serrana do município, os atuais distritos do Sana e do Glicério, onde predominava a cafeicultura (LÔBO JÚNIOR et al., 1990).

Também é válido ressaltar a importância que a pesca tem na história de Macaé, desde seus primórdios, sem nunca ter perdido sua significativa importância econômica para muitas famílias macaenses. O Mercado de Peixes, reformado e reinaugurado no ano de 2015 é um belo exemplo deste fato. Também o turismo, principalmente sob a forma de veraneio, teve relativa importância para a cidade, até a década de 1970, quando sua mais radical transformação produtiva aconteceu: a chegada da Petrobras, com a instalação de sua base no bairro da Imbetiba e as demais empresas do ramo petrolífero que vieram a reboque nos anos seguintes (PAGANOTO, 2008). Por si só, toda esta rica história pode servir de inspiração para que roteiros turísticos sejam criados e comercializados em terras macaenses, permitindo o desenvolvimento da segmentação de turismo cultural e ampliando a oferta de atividades oferecidas aos turistas que nelas chegam (DIAS, 2006). Veremos, a seguir, com mais detalhes, o impacto e as mudanças que Macaé sofreu com a exploração petrolífera em seu território. 


\section{MACAÉ E O PETRÓLEO: ENTRE A IDENTIDADE E A DEPENDÊNCIA}

Macaé, que outrora chegou a ser conhecida como "A Princesinha do Atlântico" devido à extensão e beleza de seu litoral, hoje ostenta o título de "A Capital Nacional do Petróleo". Se, por um lado, o município assumiu orgulhosamente essa imagem que a destaca no cenário brasileiro tendo erigido inclusive um monumento batizado de "Chama do Petróleo" em um dos principais acessos à cidade -, por outro, a relação entre ele e a exploração deste hidrocarboneto demonstra uma grande dependência econômica (DE CARVALHO; LOUREIRO, 2016) que, futuramente, pode comprometer seu desenvolvimento socioeconômico - já que, dentre outras questões, há um movimento global que luta pelo fim da exploração de matrizes energéticas não renováveis - e estabelecer um cenário de grande crise, como já se pôde vislumbrar, em menor escala, durante parte da década de 2010. (ZICKWOLFF et al., 2020). Com relação a tal período, Hasenclever e Fauré (2019, p. 498) destacam que, apesar de terem sido tentadas, "as iniciativas para reduzirem a dependência da economia petrolífera não foram capazes de diversificarem a economia local e impedir a volta de antigos problemas". Ou seja, para se pensar um futuro sustentável, em longo prazo, o trabalho de diversificação econômica precisa ser feito com mais atenção, organização e planejamento, contando com a participação não só das esferas governamentais e empresariais, mas do próprio povo macaense.

Nos anos 1970 a mais significativa transformação na economia macaense, até o presente momento, teve início. Segundo Piquet (2003, p.223) ela começou quando "a Petrobras elegeu a cidade de Macaé como base de operações das atividades de prospecção e de produção para o recémdescoberto petróleo da plataforma continental da Bacia de Campos". O passo seguinte foi a necessidade de adaptar a cidade às exigências da empresa quanto à edificação da estrutura física de suas instalações. A região da Imbetiba - até então um balneário muito procurado por veranistas por suas águas tranquilas para o banho de mar - foi escolhido, justamente por apresentar as características de um porto natural, para abrigar sua sede (TAVARES, et al., 2014). Com isso, como fica claro ao se analisar os dados do IBGE (2018), a chegada de novos moradores - fixos ou temporários - fez com que a população residente em Macaé passasse dos 
pouco mais de 65 mil, em 1970 - chegando a 130 mil no ano 2000 (COSTA, 2007, p.70) - para os cerca de 200 mil habitantes em 2018. Portanto, em menos de cinquenta anos, a população macaense mais que triplicou. E tal inchaço populacional acabou acarretando inúmeros contratempos para a cidade. Piquet (2013, p.228) indicou que, por conta de tal crescimento, "a cidade apresenta sobrecarga nos serviços de utilidade pública, escassez de moradias, uso predatório do litoral e outras mazelas que uma ocupação industrial sem planejamento acarreta nos locais em que se fixa". Já Costa (2007, p. 84) apontou que "a parcela mais pobre da população, no entanto, não tem acesso às mesmas condições de trabalho e moradia que são oferecidas aos extratos mais ricos, provocando uma segregação espacial na área urbana municipal”. Mazelas comuns às cidades de um país tão socialmente desigual.

Entre os dividendos e os percalços com que Macaé passou a conviver desde a chegada da Petrobras - e a posterior vinda de outras empresas estrangeiras do mesmo ramo de atividade ao seu território -, consolidou-se uma dependência econômica do município com relação ao petróleo. Este poderia ser motivo de euforia - como de fato o foi por algum tempo - já que, graças ao "ouro negro", melhorias estruturais foram implementadas na cidade e famílias locais se beneficiaram financeiramente. Porém, como afirma Bonin (2018), pode ser um grande risco para o futuro de Macaé continuar a "apostar todas as suas fichas" num porvir atrelado majoritariamente à exploração petrolífera, e para quem a diversificação econômica é uma alternativa necessária. Da Silva e Leal (2020) apontam que o modelo neoextrativista de exploração de petróleo existente em Macaé é alvo fácil para as crises econômicas e a dependência de mercados internacionais, além de excluir grande número de indivíduos da partilha de suas benesses e os perigos existentes quanto à ocorrência de acidentes ambientais nas plataformas de extração da matéria-prima. Da Silva, Becker e Martins (2015) apontam a necessidade da diminuição da prioridade dada às atividades produtivas ligadas ao petróleo, também apontando a diversificação como um caminho viável. Assim, uma alternativa para uma maior diversificação da economia local e diminuição paulatina da dependência ao petróleo seria o investimento em outras vocações já existentes no município, como o turismo, a produção agrícola, a pesca, o setor de comércio, a educação superior, dentre outras.

Nunca é demais lembrar que o petróleo é um recurso natural não renovável, o que faz com que sua exploração seja finita. Porém, a grande questão que atualmente se coloca não é tanto sobre a quantidade de petróleo ainda existente e apto a ser extraído na região da Bacia de Campos, 
nem a tecnologia exigida para a prospecção cada vez mais profunda nas águas do Oceano Atlântico, já que a Petrobras é a recordista mundial neste tipo de ação (ROSA, 2011), mas a da exploração mesma deste produto e o seu uso como matriz energética no futuro, em curto e médio prazo. Isso ocorre devido aos estudos que apontam a relação entre a queima de combustíveis fósseis - como o são todos aqueles derivados do petróleo - e o fenômeno do aquecimento global, que tem como consequências, por exemplo, o aumento da temperatura média do planeta, o derretimento das calotas polares, a elevação do nível das águas dos oceanos e o alagamento de áreas litorâneas em diversas partes do mundo, além dos danos à fauna, à flora e às populações humanas que vivem em zonas costeiras (KLABIN, 2011). Nas palavras de Zylbersztajn (2020, p. 152), “o petróleo, símbolo da pujança no século XX, tornou-se o inimigo a abater no século XXI". O autor salienta que, "no Brasil, com atraso de mais de um século, o petróleo foi apelidado de „passaporte para o futuro ${ }^{\text {,e }}$ o pré-sal, de „,bilhete premiado ${ }^{\text {ee }}$, e já no início do século estávamos apostando nosso futuro na energia do passado" (id.).

Uma maneira que Macaé tem para deixar de ser tão dependente do petróleo é, portanto, procurar sortir as atividades econômicas em seu território. Guardadas as devidas proporções, o município poderia se inspirar no exemplo de cidades como Dubai, nos Emirados Árabes Unidos, que segundo Zickwolff (2009), também teve um período de subordinação ao pecúlio proveniente da exploração petrolífera, mas que ao perceber a efemeridade de tal atividade, passou a investir no turismo, na prestação de serviços de entretenimento e lazer, na atração de sedes de empresas internacionais através de incentivos fiscais, na ampliação e transformação de seu aeroporto em um $h u b$ - local que centraliza as conexões entre voos - para a aviação internacional, além da diversificação do comércio, com a chegada de lojas de marcas estrangeiras ao país, tornando-se um local de grande destaque no cenário mundial. Obviamente o volume de arrecadação com o petróleo de Dubai é muito superior ao de Macaé, entretanto, em pequena escala, o município pode, sim, matizar suas atividades produtivas.

Como opções para a cidade, Silva (2019, p. 514) aponta para a oportunidade de transformar Macaé em uma "Capital do Conhecimento". Reconhecendo que esta seria uma conversão de longo prazo, o autor destaca o papel fundamental que as instituições de ensino superior sediadas na cidade têm, como produtoras de saberes e inovações e permitindo a democratização do acesso à informação. Para tanto, ele aposta na necessidade da criação de um "Parque Tecnológico de Macaé”, que concentraria em um mesmo espaço “empresas e instituições 
associadas que criam um ambiente favorável à inovação tecnológica” (SILVA, 2019, p. 519). Carvalho (2019) também acredita que o caminho para novos ares é a educação, no caso, o ensino superior, baseado nas diversas instituições que se instalaram no município, com destaque para a criação da Cidade Universitária, que abriga universidades públicas federais e estaduais. O autor destaca o "papel da formação profissional em consonância com o tripé ensino, pesquisa e extensão", desempenhado pela universidade, que além de democratizar saberes e acessos, melhoraria "processos políticos, socioculturais e econômicos cotidianos" e fomentaria "outra forma de expectação do futuro baseada na grandeza libertária da Educação de qualidade” (CARVALHO, 2019, p. 455). Siqueira (2021) aponta para a aposta de uma holding de empresas, em parceria com a atual gestão municipal macaense, da instalação de usinas termelétricas, à base de gás natural, que levariam Macaé a se tornar a "Capital da Energia” do Brasil. Há ainda sugestões de especialistas que apontam para o investimento nas áreas da pesca (FERREIRA et al., 2019), da agricultura familiar (LEAL e SILOTO, 2019) e do turismo (JESUS et al., 2019). Por se tratar da área de interesse do presente artigo, o tema do turismo será debatido de forma mais ampla em uma seção posterior.

A seguir, veremos a situação pela qual a cidade passou no período de quatro anos em que, devido a uma conjunção de fatores, se viu assolada por uma crise financeira e social ligada, fundamentalmente, à sua grande dependência econômica em relação à exploração do petróleo momento em que recebeu a triste alcunha de "Cidade do Desemprego" em matéria do El País (2018).

\section{A DÉCADA DE 2010 E A CRISE ECONÔMICA QUE SE INSTALOU EM MACAÉ}

Para uma melhor compreensão da crise que se instalou em Macaé entre os anos de 2014 e 2018, se faz necessário ampliar o horizonte de análise para além de suas fronteiras, já que as adversidades pelas quais passou foram constituídas por uma rede complexa de acontecimentos que estabeleceram o cenário sombrio que se abateu sobre o município. Primeiramente, não se devem perder de vista as bases do sistema econômico que, desde o século XIX, domina as relações de produção, trabalho e trocas comerciais no mundo - o capitalismo - cujos fundamentos se assentam na propriedade privada dos meios de produção, no lucro e na acumulação de capital. Em sua mais recente fase, o neoliberalismo, prega-se a diminuição da 
relevância do Estado, principalmente no que diz respeito à interferência na livre circulação nos mercados, dos bens, dos serviços e do dinheiro. Aliada a tal sistema, tem atuação primordial a chamada "globalização" - que tem suas origens ainda no século XVI, quando do início das viagens conhecidas como "grandes navegações", instituídas por povos europeus, como os portugueses, espanhóis e franceses -, um fenômeno que, através da utilização de meios de comunicação e de transportes tecnologicamente desenvolvidos, tem o poder de conectar os mais distantes lugares do planeta, "diminuindo" suas fronteiras territoriais e culturais (ANTUNES, PINTO, 2017). Esta é, aliás, uma explicação para o fato de que, ao longo das últimas décadas, Macaé tenha passado a receber empresas, empresários e trabalhadores de diversos países do mundo, principalmente após a quebra do monopólio da exploração do petróleo no Brasil, antes sob a exclusividade da Petrobras.

Quando, na década de 1990, o Brasil adotou o modelo neoliberal para nortear a economia nacional, ele ampliou a privatização de suas empresas públicas, o que acarretou um menor controle do Estado sobre elas. A Petrobras, em 1997, passou a ter o seu capital aberto no mercado da bolsa de valores e o governo brasileiro ficou na posição de seu maior acionista, o que fez com que ela se tornasse uma empresa estatal de economia mista. Foi justamente essa ação que fez com que organizações estrangeiras aportassem no país e se inserissem nas práticas de exploração e produção do petróleo e seus derivados, inclusive em Macaé. (JESUS et al. 2019). O resultado direto desses acontecimentos para o município foi a criação de novos postos de trabalho, o aumento no recebimento de impostos, o inchaço populacional, o impulso na construção civil - muitas vezes desordenada - e uma série de problemas estruturais e sociais devido a tantas mudanças em um tão curto espaço de tempo.

Com o estabelecimento dos royalties petrolíferos como a principal fonte de arrecadação municipal, Macaé se tornou extremamente dependente da atividade, o que pôde ser sentido durante a crise ocorrida em anos recentes. Mas, afinal, que fatores contribuíram para o cenário de recessão que culminou em um significativo número de demissões, no fechamento de diversos estabelecimentos comerciais e na redução dos gastos públicos do município, que assumiu uma posição de austeridade financeira?

Em primeiro lugar, à própria lógica do mercado internacional do petróleo, cujos principais produtores, como os Estados Unidos, a Rússia e os membros da Organização dos Países Exportadores de Petróleo - OPEP -, que atualmente conta com 13 países, dentre os quais a 
Arábia Saudita, os Emirados Árabes Unidos, o Irã, o Iraque, o Kuwait, e a Venezuela, controlam as metas de produção anual e fazem com que ele seja um produto que apresenta grandes variações de preço. Assim, quando a determinação é o aumento na produção de barris, o preço tende a cair, já quando o intuito é valorizar o preço do produto, é estipulada a diminuição na produção. Como explica Nader (2019, p. 236 - 237),

\begin{abstract}
Após mais de uma década de preços crescentes do petróleo no mercado internacional [...] houve a queda vertiginosa do preço do barril em meados de 2014 [...] a rápida queda de preços fez com que a indústria mundial de petróleo retraísse substancialmente os investimentos na exploração de novas áreas e no desenvolvimento da produção de novos campos petrolíferos, pois havia uma incerteza no mercado sobre o patamar que o preço do barril poderia alcançar e quais os fatores poderiam contribuir para sua recuperação.
\end{abstract}

Todavia, a queda nos preços do petróleo é apenas um dos fatores da crise. Somada a ela, o Brasil também passava por um delicado momento político, com a reeleição de Dilma Rousseff à presidência, em uma conjuntura de recessão econômica que culminou com os protestos populares de julho de 2013. Em estreita relação com a questão política do país, houve também a instituição da Operação Lava Jato, que descobriu esquemas de corrupção envolvendo a Petrobras e que também atingiu o governo do Estado do Rio de Janeiro e algumas "empresas investigadas, suspensas de negociarem com a Petrobras, que pediram concordata e possuíam bases operacionais com contratos em vigência com a companhia" (NADER, 2019, p. 238). Desta forma, a Petrobras foi submetida a uma asfixia financeira, e precisou diminuir todos os seus investimentos, inclusive em Macaé. Por fim, a arrecadação de royalties do município também sofreu uma forte redução. A soma de todos estes fatores levou Macaé a uma situação caótica, que só começou a apresentar melhorias a partir do ano de 2018, quando os preços do petróleo voltaram exibir tendências de crescimento e a Petrobras iniciou seu processo de paulatina recuperação.

E então, no início de 2020, a pandemia de coronavírus chegou ao Brasil, trazendo novos cenários de incerteza que, devido a uma série de ações desastrosas por parte do Governo Federal, ainda se faz presente, minando a economia do país e, macabramente, ceifando centenas de milhares de vidas humanas $-728^{6}$ delas no município de Macaé, onde 30.637 pessoas foram

\footnotetext{
${ }^{6} \mathrm{O}$ município de Macaé conta, segundo o IBGE (2021), com uma população estimada de 266.136 pessoas. Assim, aproximadamente $0,27 \%$ de seus residentes faleceram devido à pandemia de Coronavírus e 11,5\% foram
} 
contaminadas até o dia 31 de agosto de 2021 (PREFEITURA DE MACAÉ, 2021). Todavia, mesmo com este panorama nefasto, a cidade tem conseguido, dentro de suas possibilidades, se manter em uma condição melhor do que aquela por que passou entre 2014 e 2018, economicamente falando. Como? Novamente a resposta está no petróleo e na gradual recuperação de seu valor no mercado internacional. Sobre a ocupação hoteleira no município, nos últimos doze meses, Kina (2021) explica que "além do estabelecimento de protocolos rígidos, os hotéis receberam uma demanda grande do segmento offshore. Também por questão de protocolo, empresas do ramo exigem uma quarentena de funcionários vindos de fora, processo realizado nos hotéis".

Após ter vivenciado um período sério de crise e de apresentar uma relativa recuperação nos últimos dois anos, Macaé precisa decidir como irá se estruturar economicamente pensando no seu futuro em longo prazo. Para tanto é imprescindível que o poder público, em parceria com a iniciativa privada e com os conhecimentos provenientes da academia se unam para pensar, debater e delinear estratégias visando um porvir mais sustentável e potencialmente benéfico aos seus cidadãos. Morin (2020, p. 32), nos lembra que "a crise numa sociedade suscita dois processos contraditórios. O primeiro estimula a imaginação e a criatividade na busca de soluções novas. $\mathrm{O}$ segundo é a busca do retorno à estabilidade passada ou a adesão a uma salvação providencial”. Assim, Macaé deve determinar se permanecerá atrelando sua história ao petróleo, mesmo sabendo de todos os riscos que essa opção pode suscitar, ou se iniciará um processo de diversificação econômica ampla, cujo horizonte não apresente um viés sumamente imediatista. Uma das alternativas para que isso ocorra pode ser encontrada através da atividade turística, que já existe no município, e será analisada mais minuciosamente na próxima seção.

\section{A ATIVIDAde TURística EM MACAÉ: PASSAdo, PRESENTE E FUTURos POSSÍVEIS}

O turismo é uma atividade produtiva de prestação de serviços que possui um significativo potencial de desenvolvimento econômico por conta do seu "efeito multiplicador" - devido à necessidade constante de abastecimento de diversos produtos, como alimentos, bebidas, eletrodomésticos, mobiliário, roupa de cama, de banho e de mesa, combustíveis, dentre muitos 
outros, além de serviços de manutenção. Quando se percebe que fazem parte do turismo os serviços de hospedagem, transporte de passageiros, alimentação, prestação de informações turísticas, eventos de lazer ou corporativos, além de diferentes tipos de entretenimento, pode-se vislumbrar o tamanho da rede de relações de negócios estabelecida para atender às demandas turísticas (TRIBE, 2003).

Até a década de 1970, segundo Tavares et al. (2014), a cidade de Macaé era procurada por viajantes em busca de lugares aprazíveis, de belas paisagens, para descansar e tomar banhos de mar. Dentre todas as suas praias, a de Imbetiba era a que atraía o maior número de veranistas. No local foi erigido o Hotel Balneário da Imbetiba, em 1889, e coube a Antônio José Domingues de Oliveira a concessão de 40 anos para a gestão do empreendimento. Após o fim deste período, assumiu o comando do hotel o historiador Alberto Frederico de Moraes Lamego. Já em 1950, sob uma nova direção, o negócio foi transformado em colônia de férias que, oito anos depois, após reformas, passou a ser gerida pelo SESC - Serviço Social do Comércio. No fim da década de 1980, o SESC fechou a unidade, cujo prédio ainda foi usado como um bar e, finalmente, alugado pela Petrobras para fins de logística (SÉRIE, 2020). Assim, através da trajetória do Hotel Balneário, podemos perceber que a relação macaense com o turismo é longeva, e que o título de "Princesinha do Atlântico" que ostentou por muito tempo tem sua razão de ser.

Quando a Petrobras instalou sua sede, em 1979, justamente na região da Imbetiba, esse apelo veranista foi obnubilado, mas o turismo não desapareceu de Macaé, apenas se transformou. Se antes a cidade era procurada para o lazer, com o passar do tempo e do estabelecimento da indústria petrolífera em seu território entraram em cena o turismo de negócios ${ }^{7}$ e as viagens corporativas. Wada (2009, p. 215) explica que o "turismo de negócios é o conjunto de atividades que resultam em viagens sob a responsabilidade de uma pessoa jurídica [...] que absorve todas as despesas previstas em sua política de viagem", conceito que o aproxima daquele dado por Martins e Murad Júnior (2018, p. 18) para as viagens corporativas, que seriam "viagens individuais ou coletivas, feitas frequentemente por profissionais liberais, funcionários, terceiros ou convidados de empresas e pagas por um CNPJ com objetivos profissionais ou decorrentes deles".

\footnotetext{
${ }^{7}$ Segundo a Prefeitura de Macaé (2016), naquele ano o turismo de negócios era responsável por 10\% do PIB municipal.
} 
Segundo Barbosa e Da Silva (2017), o crescimento da hotelaria em Macaé, objetivando atender aos trabalhadores e empresários do ramo do petróleo, se deu de forma vertiginosa desde a efetivação da exploração da Bacia de Campos, o que a levou a ter, com o passar do tempo, a segunda maior rede hoteleira do Rio de Janeiro, ficando atrás apenas da capital do estado. Até o período da crise que se instalou no município, entre 2014 e 2018, os maiores hotéis da cidade haviam se especializado em atender o público corporativo, apresentando taxas de ocupação próximas de $100 \%$ durante os dias úteis ao longo de todo o ano. Isso os levou a uma atitude de acomodação, que cobrou um preço alto no período mais crítico, quando as viagens de negócio se reduziram significativamente. Para lidar com a situação, parte desses meios de hospedagem adotou um plano de adaptação ao turismo de lazer, combinada com a redução dos preços das diárias. Além disso, Segundo Silveira (2019), a Prefeitura de Macaé, através da Secretaria Adjunta de Turismo de Macaé e em parceria com outras secretarias de governo, procurando ampliar o poder de atratividade do município, organizou um calendário de eventos turísticos, cuja realização ficou a cargo da iniciativa privada, mas contando com o apoio institucional da gestão pública municipal. O sucesso do calendário fez com que ele fosse mantido como parte da estratégia da secretaria para o desenvolvimento da atividade turística de Macaé, mesmo após o arrefecimento da crise, quando as empresas voltaram a procurar a cidade como destino de negócios. Todavia, após o estabelecimento da pandemia de Covid-19, os eventos tiveram que ser suspensos, e assim continuam até o presente momento, o que acarretou, novamente, uma diminuição nas taxas de ocupação dos hotéis da cidade (MEDEIROS, 2020).

Alguns especialistas, como Lummertz (2020) e Jereissati Filho (2020) acreditam que, ao menos em curto prazo, após a erradicação da pandemia de Covid-19 poucos viajantes estarão seguros para realizar deslocamentos para destinos longínquos, que exijam muitas horas em um avião, por exemplo. A tendência seria, por outro lado, realizar viagens curtas para locais próximos, o que beneficiaria o turismo interno no país. Segundo Medina (2020, p. 148), “os turistas brasileiros gastam, todos os anos, 75 bilhões de reais no exterior. Com a eclosão da pandemia, milhares desses turistas foram surpreendidos lá fora com o risco iminente de adoecer e com toda a sorte de dificuldades de voltar ao Brasil". Ainda segundo o autor, o viajante brasileiro "hoje teme sair do país em viagens de lazer e compras" (id.), ou seja, o turismo interno tende a se tornar uma opção mais viável e uma parcela considerável do dispêndio financeiro externo deverá permanecer em solo brasileiro, ampliando a atividade turística nacional. 
Por integrar a região turística fluminense da Costa do Sol - também composta pelos municípios de Araruama, Armação dos Búzios, Arraial do Cabo, Cabo Frio, Carapebus, Casimiro de Abreu, Iguaba Grande, Maricá, Quissamã, Rio das Ostras, São Pedro da Aldeia, Saquarema estabelecida pela Companhia de Turismo do Estado do Rio de Janeiro - TurisRio, Macaé pode se beneficiar com a perspectiva do incremento do turismo local. A característica principal de todas as localidades da Costa do Sol é o apelo de seu litoral, suas praias, e as atividades relacionadas com o veraneio. Há, entretanto, características peculiares que as distinguem umas das outras e as tornam mais ou menos atrativas para o turismo de lazer. As cidades que mais se destacam neste quesito são Araruama, Armação dos Búzios, Arraial do Cabo, Cabo Frio e Saquarema que, conforme Ramão (2016) possuem ampla presença de "segundas residências", além de diferentes meios de hospedagem, com destaque para as pousadas.

Macaé, por outro lado, tornou-se um destino vinculado ao turismo de negócios e estruturou em seu território uma rede hoteleira extensa e plural. Assim, uma perspectiva real para o futuro da atividade turística em Macaé, a partir desta estrutura consolidada de hospitalidade que, segundo a Prefeitura de Macaé (2016), contava com cerca de 4.300 unidades habitacionais (UHs) e 12.000 leitos no ano de 2016, majoritariamente voltados para o turismo corporativo e que também inclui uma diversificada gastronomia - com destaque para o Polo Gastronômico Praia dos Cavaleiros (2021), reunindo 15 restaurantes na região mais nobre da cidade - é servir de base para que os visitantes da Costa do Sol, a partir do território macaense, conheçam seus diferentes destinos e retornem diariamente para desfrutarem da qualidade dos serviços de hospedagem e restauração de Macaé. O fato de possuir um aeroporto estruturado que, segundo Brum (2021), passará por reformas e ampliação através de investimentos da ordem de 160 milhões de reais - com previsão para término em 2023 - e que é considerado o principal do Brasil para o atendimento de operações offshore, é mais um ponto positivo para a cidade neste sentido. Recentemente ele voltou a operar voos comerciais, em dois horários semanais para o aeroporto Santos Dumont, na capital fluminense, que conecta o estado com outras cidades do país. A companhia aérea Azul, utilizando aeronaves com capacidade para 70 passageiros é quem realiza o trajeto atualmente. Para a concessionária que administra o aeroporto macaense, a Zurich Airport Brasil, "a retomada dos voos comerciais busca atender a demanda de mobilidade da região, que além de ser referência nacional no ramo offshore, se destaca pela infraestrutura de turismo e de negócios" (AEROPORTO, 2021). 
Além disso, há as próprias atrações do município que podem ser incrementadas visando à transição que se dará quando, cedo ou tarde, o ciclo do petróleo chegar ao fim. Como exemplos de atrativos, destacam-se o distrito Sana - localizado na região serrana de Macaé, é uma Área de Proteção Ambiental - que já atrai diversos visitantes interessados no ecoturismo e no turismo de aventura, buscando um contato mais próximo com a natureza, na realização de trilhas em meio à mata - cujo ponto culminante é a chegada à Pedra do Peito do Pombo -, em passeios a cavalo, em banhos de rio e cachoeira, além de possuir um grande potencial, ainda não explorado, para receber estudiosos da vida de pássaros - o turismo ornitológico - uma vez que há mais de cem espécies de aves já catalogadas na região. Bonin $(2017 ; 2020)$, também chama a atenção para o turismo rural que pode agregar ainda mais valor ao destino, e incrementar a renda das famílias que atuam na pequena produção agrícola local. Há, também, o Parque Nacional Municipal de Atalaia, que oferece visitas guiadas, áreas para piquenique e lazer, além de ações de educação ambiental. A Fazenda Airis, remanescente da história da produção cafeeira em território macaense e que conta com uma grande coleção de móveis coloniais, além da Lagoa de Imboassica, com ótimas condições para a prática de esportes aquáticos, além da contemplação paisagística, principalmente no período do pôr-do-sol (JESUS et al., 2019).

Macaé também conta com uma série de recursos, tanto naturais quanto culturais, que podem, caso recebam o aporte de infraestrutura necessária, se transformar em atrativos, de fato. Todos eles apresentam potencialidade para diversificar a atividade turística macaense, ampliando sua atração como um destino de lazer. Dentre outros, evidenciamos o Forte Marechal Hermes, cujo acesso é limitado devido ao seu modelo de gestão pelo Exército Brasileiro, mas que pode se inspirar no Forte de Copacabana, na cidade do Rio de Janeiro, e na Fortaleza de Santa Cruz, no município de Niterói, que recebem turistas, realizam visitas guiadas e contam com estruturas para a realização de eventos particulares, além de lanchonetes e restaurantes (VIEIRA, 2014); o Arquipélago de Sant ${ }^{e e}$ Anna, cujas águas atrairiam turistas interessados no mergulho esportivo e em atividades náuticas, mas que também possui restrições de uso devido à gestão da Marinha do Brasil; e o Parque Nacional da Restinga de Jurubatiba, que é gerido pelo ICMBio e faz parte dos municípios de Quissamã, Carapebus e Macaé, e que apesar de já apresentar projetos de uso turístico, ainda não consolidou suas ações (JESUS et al., 2019).

Quanto aos atrativos completamente inovadores que poderiam ser implementados, Monteiro e Guerreiro (2015) analisaram um caso emblemático ocorrido na Malásia, onde 
plataformas de exploração de petróleo aposentadas foram transformadas em resorts flutuantes, com diversas opções de lazer e especializadas em mergulhos esportivos, o que poderia ocorrer caso a Petrobras e empresários do ramo hoteleiro, através de intermediação do poder público, estabelecessem uma parceria. Mais uma ideia seria a criação de um "Museu do Petróleo", no qual os visitantes pudessem ter contato com esta cadeia produtiva que, em algum momento, será definitivamente relegada ao passado, mas cuja história foi, e ainda é fundamental para Macaé. Outra vertente que pode ser explorada em um futuro próximo, caso siga obtendo pareceres favoráveis no Senado Federal, como aponta Possamai (2020), diz respeito à legalização dos cassinos, que poderiam ser adaptados à hotelaria já existente no município, atraindo uma demanda retraída que busca essa atividade em destinos internacionais como Las Vegas, Aruba, Curaçao e Punta del Este.

Por fim, cabe destacar a importância da Educação para o futuro da atividade turística de Macaé. Seja através dos eventos acadêmicos - simpósios, palestras, seminários, jornadas científicas, entre outros - que já são realizados na cidade devido à presença de diversos cursos universitários e que podem ser potencializados com ações efetivas voltadas para tal fim (CARVALHO, 2019), ou das necessárias pesquisas de oferta e demanda no município, que segundo Stigliano e César (2006) são fundamentais para o planejamento e a execução das ações do turismo. A oferta de cursos de qualificação da mão-de-obra local, seja de nível técnicoprofissionalizante, como já ocorre em Saquarema com a parceria entre a prefeitura e a rede Faetec$\mathrm{RJ}^{8}$ (SECRETARIA, 2021), ou de nível superior, voltada para as áreas de turismo, hospitalidade e organização de eventos, e que devem atender tanto aos profissionais que já atuam nestas áreas, buscando sua reciclagem, principalmente no que se refere aos procedimentos que serão exigidos após o término da pandemia, quanto para a formação de novos trabalhadores, capazes de prestar serviços de qualidade aos visitantes. Aliás, Macaé poderia, também, oferecer para a educação básica uma disciplina sobre turismo na rede municipal de educação, fazendo com que os alunos já tomassem contato e gosto pela atividade desde a mais tenra idade.

Independentemente do tipo de turismo em questão, é de extrema importância que ele seja feito da maneira mais sustentável possível, levando em conta suas esferas econômica, social, ambiental, política e cultural. A Organização Mundial do Turismo - órgão ligado à ONU e que

\footnotetext{
${ }^{8}$ Fundação de Apoio à Escola Técnica do Estado do Rio de Janeiro.
} 
atua como um fórum global para o debate de políticas relacionadas com a atividade turística define o "turismo sustentável" como aquele que

Atende às necessidades dos turistas de hoje e das regiões receptoras, ao mesmo tempo em que protege e amplia as oportunidades para o futuro. É visto como um condutor ao gerenciamento de todos os recursos, de tal forma que as necessidades econômicas, sociais e estéticas possam ser satisfeitas sem desprezar a manutenção da integridade cultural, dos processos ecológicos essenciais, da diversidade biológica e dos sistemas que garantem a vida. (OMT, 2003, p. 24).

Concordando com Zickwolff et al. (2020) quando defendem que uma atividade humana plenamente sustentável não existe, a não ser como uma utopia retórica, ainda assim é preciso que todos os esforços sejam feitos, por todos os envolvidos no desenvolvimento do turismo em Macaé, para que haja um equilíbrio na distribuição das benesses advindas da atividade e que estas cheguem até a população local na forma de melhorias estruturais e na sua qualidade de vida, que sua cultura não seja desvalorizada, seu meio ambiente sofra o mínimo de impactos possíveis e que as demandas à cargo do poder público municipal não sejam descontinuadas por questões político-partidárias ao longo do tempo, mas que o futuro a longo prazo seja sempre o norte que oriente as suas ações.

\section{CONSIDERAÇÕES FINAIS}

Macaé precisa, urgentemente, decidir que caminho percorrerá em busca de sua sustentabilidade econômica e social. Se ela permanecerá atrelada majoritariamente à produção petrolífera, tranquila e impassível, até que tal atividade se torne inviável e se extinga, assistindo as diversas empresas do ramo partir de seu território - sem olhar para trás, e abandonando uma série de estruturas obsoletas -, ou se começará a diversificar sua economia, buscando novas opções de negócios que permitam que o fim do ciclo do petróleo, seja lá quando ele ocorrer, não a afunde em uma crise caótica, sujeitando-a ao desemprego em massa, ao aumento da situação de pauperização

de sua população e a um movimento inverso daquele que conheceu nos últimas décadas, ou seja, o de saída de pessoas de seu território em busca de uma vida melhor em outras paragens. 
O turismo, de diversos tipos, e realizado da maneira mais sustentável possível, pode ser uma das alternativas para que Macaé, de fato, diversifique seu cabedal de atividades produtivas, ajudando-a a superar o ocaso da exploração petrolífera que, cedo ou tarde, por sua escassez ou pela pressão de movimentos ambientais internacionais, acontecerá. Após os cenários caóticos de crise econômica e de pandemia viral, algumas ações já vêm sendo tomadas e outras mais poderão ser desenvolvidas. Este trabalho procurou apontar algumas possibilidades aparentemente viáveis para isto. Ainda assim, justamente por se pensar em horizontes potenciais, o tempo pode, impiedosamente, frustrar todo o quadro aqui prognosticado. Todavia, insistimos na necessidade de se labutar para tentar contribuir, de alguma maneira, com a construção de um porvir exitoso para Macaé, seu povo e todos aqueles que a amam. É preciso que mais estudos sejam realizados quanto à importância e as possibilidades de desenvolvimento do turismo no município de Macaé. Que este trabalho possa servir de estímulo a outros pesquisadores e que seja apenas mais uma peça no grande painel do conhecimento ora em construção.

\section{REFERÊNCIAS}

AEROPORTO de Macaé, RJ, volta a oferecer voos comerciais a partir deste mês. G1 - Região dos Lagos, 03 mai. 2021. Disponível em: https://g1.globo.com/rj/regiao-doslagos/noticia/2021/05/03/aeroporto-de-macae-rj-volta-a-oferecer-voos-comerciais-a-partir-deste mes.ghtml. Acesso em 25 ago. 2021.

ANTUNES, R.; PINTO, G. A.. A fábrica da educação: da especialização taylorista à flexibilização toyotista. São Paulo: Cortez, 2017.

BARBOSA, L. O. de M.; SILVA. S. C.. O circuito espacial de produção do petróleo e a rede hoteleira de Macaé/RJ: reflexões sobre a especialização territorial. Boletim Petróleo, Royalties e Região - Campos dos Goytacazes/RJ - Ano XV, no 58 - dezembro/2017. Disponível em: https://royaltiesdopetroleo.ucam-campos.br/wp-content /uploads/2017/12/UCAM__PIT_4627A_Pg3a10_Luiz-Ota\%CC\%81vio-de-Moura-Barbosa-_ Acesso em 25 ago. 2021.

BONIN, N. J. Z.. A atividade petrolífera como vetor de transformações econômicas e socioespaciais em Macaé, RJ. Terr@Plural, Ponta Grossa, v.12, n.1, p. 41-61 jan/abr. 2018. Disponível em: https://www.revistas.uepg.br/index.php/tp/article/view/9918 /209209210144. Acesso em: 25 ago. 2021.

BONIN, N. J. Z.. As potencialidades turísticas e sua contribuição para o rural de Macaé. Ágora. Santa Cruz do Sul, v.19, n. 02, pp. 45-53, jul./dez. 2017. Disponível em: file://C:/Users/ErickCoelho/Downloads/9726-45694-1-PB.pdf. Acesso em: 25 ago. 2021. 
BONIN, N. J. Z.. Ecoturismo, produção agrícola e as possibilidades do turismo rural no Sana (Macaé-RJ). Geofronter, Campo Grande, v. 6, pp. 01-16, 2020. Disponível em: https://core.ac.uk/download/pdf/327172909.pdf. Acesso em 25 ago. 2021.

BRUM, J. V. Aeroporto de Macaé, RJ, anuncia investimento de R \$ 160 milhões para construção de novo terminal. G1 - Macaé, 11 mai. 2021. Disponível em: <https: //g1.globo.com/rj/regiaodos-lagos/noticia/2021/05/11/aeroporto-de-macae-rj-anuncia-investimento-de-r-160-milhoespara-construcao-de-novo-terminal.ghtml>.Acesso em 25 ago. 2021.

CARVALHO, M. R. de. Universidade pública e desenvolvimento local: a experiência de Macaé na transição de capital nacional do petróleo à cidade do conhecimento. In: SILVA, S, R, de A, e; CARVALHO, M, R, de (Orgs.). Macaé, do caos ao conhecimento: olhares sobre o cenário de crise econômica. Macaé, RJ: Prefeitura Municipal de Macaé, 2019.

COSTA, R. C. R. da. Exclusão social e desenvolvimento humano: análise sociológica da pesquisa domiciliar do programa Macaé cidadão 2001 - 2003. Macaé, RJ: Prefeitura Municipal de Macaé, 2007.

SILVA, J. A. A.; BECKER, B. R.; MARTINS, R. L. Macaé e a sustentabilidade do projeto de "capital nacional do petróleo". Espaço e Economia [Online], 7, 2015. Disponível em: https://journals.openedition.org/espaçoeconomi a/1875. Acesso em: 25 ago. 2021.

SILVA, M. T.; LEAL, G. F.. A insustentabilidade do trabalho de Sísifo: observações críticas sobre o desenvolvimento sustentável a partir do caso de Macaé-RJ. Estudo de Administração e Sociedade V.5, N.1(2020) pp. 13-27. Disponível em: https://perio dicos.uff.br/revistaeas/article/view/42603/27566. Acesso em: 25 ago. 2021.

CARVALHO, L. J.; LOUREIRO, C. F. B.. Território, desigualdade e expansão do capital: a centralidade da indústria do petróleo em Macaé/RJ. Revista Eletrônica do Programa de PósGraduação em Geografia - UFPR, Curitiba, v. 11, n. 1, p. 26-46, julho 2016. Disponível em: https://revistas.ufpr.br/geografar/article/view/48976. Acesso em: 26 ago. 2021.

DIAS, R.. Turismo e patrimônio cultural: recursos que acompanham o crescimento das cidades. São Paulo: Saraiva, 2006.

EL PAÍS. Macaé, do Eldorado do petróleo à terra do desemprego. Disponível em: <https://brasil.elpais.com/brasil/2015/11/04/economia/1446645908_814221.html>. Acesso em: 09 ago. 2018.

FERREIRA, M. I. P.; MAFORT, A. V. L.; SILVA, E. R. da; SILVA, N. R. da; AZEVEDO, A. de. A pesca como potencial de desenvolvimento econômico no município de Macaé. In: SILVA, S. R. de A.; CARVALHO, M. R. de (Orgs.). Macaé, do caos ao conhecimento: olhares sobre o cenário de crise econômica. Macaé, RJ: Prefeitura Municipal de Macaé, 2019.

FRANCO, M. da C. V.. História: a antiga Macaé. Prefeitura Municipal de Macaé. Disponível em: <http://www.macae.rj.gov.br/conteudo/leitura/título/historia>. Acesso em: 07 jul. 2021. 
HASENCLEVER, L.; FAURÉ, Yves-André. Limites dos arranjos produtivos locais: Macaé no cenário de reconfiguração da cadeia de petróleo e gás. In: SILVA, S. R. de A. e; CARVALHO, M. R. de (Orgs.). Macaé, do caos ao conhecimento: olhares sobre o cenário de crise econômica. Macaé, RJ: Prefeitura Municipal de Macaé, 2019.

IBGE. Macaé. Disponível em: https://cidades.ibge.gov.br/brasil/rj/macae/panorama. Acesso em 12 out. 2018.

IBGE. Cidades e Estados. Disponível em: https://www.ibge.gov.br/cidades-eestados/rj/macae.html. Acesso em 01 set. 2021.

JEREISSATI FILHO, C.. Uma oportunidade para repensar o futuro. In: O mundo pós-pandemia: reflexões sobre uma nova vida. NEVES, J. R. de C. (Org.). Rio de Janeiro: Nova Fronteira, 2020.

JESUS, A. C.; ZICKWOLFF, E. da C. C.; CALDAS, G. H. S.; Silva, L. A. da. A crise econômica da década de 2010 e seus efeitos sobre o turismo no município de Macaé. In: SILVA. S. R. de A. e; CARVALHO, M. R. de (Orgs.). Macaé, do caos ao conhecimento: olhares sobre o cenário de crise econômica. Macaé, RJ: Prefeitura Municipal de Macaé, 2019.

KINA, Lucas. Um ano depois, voltamos a Macaé(RJ). Hoteliernews. 2021. Disponível em: <https://www.hoteliernews.com.br/um-ano-depois-voltamos-a-macae-rj/>. Acesso em: 14 jun. 2021.

KLABIN, Israel. A urgência do presente: biografia da crise ambiental. Rio de Janeiro: Elsevier, 2011.

LEAL, Giuliana Franco; SILOTO, Denise Aparecida Pereira. Onde o rural e o urbano se encontram: a importância das feiras de agricultores para Macaé. In: SILVA. S. R. de A. e; CARVALHO, M. R. de (Orgs.). Macaé, do caos ao conhecimento: olhares sobre o cenário de crise econômica. Macaé, RJ: Prefeitura Municipal de Macaé, 2019.

LEAL, José Agostinho Anachoreta; SERRA, Rodrigo Valente. A experiência do Alasca. In: PIQUET, Rosélia; CRUZ, José Luis Vianna da; VILANI, Rodrigo Machado. O desafio da abundância: 10 anos do Boletim Petróleo, Royalties e Região. Rio de Janeiro: Garamond, 2013.

LÔBO JÚNIOR, D. T.; MORAIS, R. Q. de M.; SANTOS, S. R. de S. L. dos; GAVINHO, V. Mateus dos Santos. Macaé síntese geo-histórica. Rio de Janeiro: 100 Artes Publicações, 1990.

LUMMERTZ, V. O que será do turismo depois da Covid-19. In: O mundo pós-pandemia: reflexões sobre uma nova vida. NEVES, José Roberto de Castro (Org.). Rio de Janeiro: Nova Fronteira, 2020.

MARTINS, V. G.; MURAD JÚNIOR, E.Viagens corporativas. São Paulo: Aleph, 2010. 
MEDEIROS, V. Enquanto isso em Macaé... Hotelier News-Hospitalidade em Movimento. 3 abr. 2020. Disponível em: https://www.hoteliernews.com.br/enquanto-isso-em-macae/ . Acesso em: 25 ago. 2021.

MEDINA, R. O que não vai mudar depois da pandemia: a natureza humana. In: O mundo póspandemia: reflexões sobre uma nova vida. Rio de Janeiro: Nova Fronteira, 2020.

MIELKE, E. J. C. Comercialização em turismo: a cooperação no desenvolvimento de destinos turísticos. In: PANOSSO NETTO, Alexandre; ANSARAH, Marília Gomes dos Reis (EE.). Produtos turísticos e novos segmentos de mercado: planejamento, criação e comercialização. Barueri, SP: Manole, 2015.

MONTEIRO, E. da S.; GUERREIRO, E. P.. Turismo e serviços nas plataformas de petróleo: novo segmento? In: PANOSSO NETTO, Alexandre; ANSARAH, Marília Gomes dos Reis (EE.). Produtos turísticos e novos segmentos de mercado: planejamento, criação e comercialização. Barueri, SP: Manole, 2015.

MORIN, E. É hora de mudarmos de via: as lições do coronavírus. Rio de Janeiro: Bertrand Brasil, 2020.

NADER, G. Os impactos da recente crise do setor de petróleo em Macaé. In: SILVA. S. R. de A. e; CARVALHO, M. R. de (Orgs.). Macaé, do caos ao conhecimento: olhares sobre o cenário de crise econômica. Macaé, RJ: Prefeitura Municipal de Macaé, 2019.

OMT. Guia de desenvolvimento do turismo sustentável. Porto Alegre: Bookman, 2003.

PAGANOTO, F. Mobilidade e trabalho em Macaé/RJ, a "capital do petróleo". Dissertação. 2008. Dissertação. (Mestrado em Geografia) - Universidade Federal do Rio de Janeiro, Rio de Janeiro, 2008.

PIQUET, R.. Da cana ao petróleo: uma região em mudança. In: PIQUET, Rosélia (Org.).

Petróleo, royalties e região. Rio de Janeiro: Garamond, 2003.

POLO GASTRONÔMICO PRAIA DOS CAVALEIROS. Conheça melhor o polo. Disponível em: http://www.polocavaleiros.com.br/conhecamelhor.html. Acesso em 25 ago. 2021.

POSSAMAI, C.. Legalização dos cassinos no Brasil recebe parecer favorável em comissão do Senado. Igaming Brazil. Disponível em: https://igamingbrazil.com/legislacao /2020/10/23/legalizacao-dos-cassinos-no-brasil-recebe-parecer-favoravel-em-comissao-dosenado/. Acesso em: 11 jun. 2021.

PREFEITURA DE MACAÉ. Informe coronavírus. Disponível em: http://www.macae.rj.gov.br/conteudo/leitura/titulo/informe-coronavirus. Acesso em: 01 set. 2021.

PREFEITURA DE MACAÉ. Macaé Showcase. Edição 2016. Disponível em: http://macae.rj.gov.br/midia/uploads/SHOWCASE\%20-\%20TURISMO.pdf. Acesso em: 25 ago. 2021. 
RAMÃO, F. de S. As residências secundárias e a exploração da praia: o eixo Cabo Frio-Arraial do Cabo-Armação dos Búzios no Estado do Rio de Janeiro. XVIII Encontro Nacional de

Geógrafos. 24 a 30 jul. 2016. São Luiz, MA. Disponível em: http://www.eng2016.agb.org.br/resources/anais/7/1466277565_ARQUIVO_ENG2016ASRESID ENCIASSECUNDARIASEAEXPLORACAODAPRAIA.pdf. Acesso em: 25 ago. 2021.

ROSA, L. P.. Fontes alternativas de energia no Brasil e no mundo. In: NUSSENZVEIG, H. Moisés. O futuro da terra. Rio de Janeiro: Editora FGV, 2011.

SECRETARIA de Turismo solicita convênio com FAETEC Bacaxá. Prefeitura de Saquarema. 11 mar. 2021. Disponível em: https://www.saquarema.rj.gov.br/secretaria-de-turismo-solicitaconvenio-com-faetec-bacaxa/. Acesso em: 25 ago. 2021.

SÉRIE desvendando Macaé: Grande Hotel Balneário de Imbetiba - Desde 1889. ALERJ, 2020. Disponível em: https://cliquediario.com.br/artigos/serie-desvendando-macae-grande-hotelbalneario-de-imbetiba-desde-1889 Acesso em: 10 jun. 2021.

SILVA, C. E. L. da. Macaé: novos modelos de negócios para diversificação da economia. In: SILVA. S. R. de A. e; CARVALHO, M. R. de (Orgs.). Macaé, do caos ao conhecimento: olhares sobre o cenário de crise econômica. Macaé, RJ: Prefeitura Municipal de Macaé, 2019.

SILVEIRA, J. Prefeitura lança calendário de eventos turísticos 2019. Prefeitura Municipal de Macaé. 2019. Disponível em: http://www.macae.rj.gov.br/noticias/leitura/noticia/prefeitu ralanca-calendario-de-eventos-turisticos-2019. Acesso em 25 ago. 2021.

SIQUEIRA, M.. Prefeitura viabiliza instalação de novas termelétricas. Prefeitura Municipal de Macaé. 2021. Disponível em: http://www.macae.rj.gov.br/noticias/leitura /noticia/prefeituraviabiliza-instalacao-de-novas-termeletricas. Acesso em: 14 jun. 2021.

STIGLIANO, B. V.; CÉSAR, P. de A. B.. Inventário Turístico. Campinas, SP: Alínea, 2006.

TAVARES, A. F.; CAUTIERO, G. M. dos S.; FRANCO, M. C. V. (Orgs.). Relatos e personagens na história de Macaé. Macaé, RJ: Solar dos Mellos, 2014.

TRIBE, J. Economia do lazer e do turismo. $2^{\text {a }}$ Ed. São Paulo: Manole, 2003.

VIEIRA, L. Fortes no Rio de Janeiro. Guia da Semana. 2014. Disponível em: https:// www.guiadasemana.com.br/turismo/noticia/fortes-no-rio-de-janeiro. Acesso em 25 ago. 2021.

WADA, E. K.. Turismo de negócios: viagens corporativas, eventos e incentivos. In: PANOSSO NETTO, Alexandre; ANSARAH, Marília Gomes dos Reis (EE.). Segmentação do mercado turístico: estudos, produtos e perspectivas. Barueri, SP: Manole, 2009.

ZICKWOLFF, E. da C. C. A turística flor do deserto, entre o lugar e o não-lugar: um estudo sobre a cidade de Dubai. Niterói, RJ: UFF, 2009. (Monografia).

ZICKWOLFF, E. da C. C.; JESUS, A. C.; SILVA, L. A. da; HATAB, V. S.; CALDAS, G. H. S.. Turismo em Macaé: possibilidades para um desenvolvimento mais sustentável da 
atividade. Estudos de Administração e Sociedade, Niterói, RJ, v. 5, ed. 1, p. 78-93, 2020. Disponível em: https://periodicos.uff.br/revistaeas/issue/view/2388/508. Acesso em: 07 jun. 2021.

ZYLBERSZTAJN, D. Apenas os princípios da natureza serão preservados. In: O mundo póspandemia: reflexões sobre uma nova vida. NEVES, J. R. de C. (Org.). Rio de Janeiro: Nova Fronteira, 2020. 